Acta Scientifica Malaysia (ASM)

DOI: http://doi.org/10.26480/asm.01.2020.14.18

ZIBELINE INTERNATIONAL

ISSN: 2521-5051 (Print)

ISSN: 2521-506X (Online)

CODEN: $A S M C C Q$

RESEARCH ARTICLE

\title{
URINARY LEAD CONCENTRATION IN CHRONIC KIDNEY DISEASE PATIENTS AT NEPHROLOGY CLINIC IN SABAH
}

\author{
Crisdy Entinga*, Shamsul Bahari Shamsudina, Khamisah Awang Lukman ${ }^{b}$ \\ a Department of Community and Family Medicine, Faculty Medicine and Health Science \\ boccupational Safety and Health Center, University Malaysia Sabah Jalan UMS, 88400, Kota Kinabalu, Sabah, Malaysia. \\ *Corresponding Author Email: crisdy79@gmail.com
}

This is an open access article distributed under the Creative Commons Attribution License CC BY 4.0, which permits unrestricted use, distribution, and reproduction in any medium, provided the original work is properly cited

\section{ARTICLE DETAILS}

Article History:

Received 01 December 2019

Accepted 06 January 2020

Available online 07 February 2020

\begin{abstract}
Presently, scientific knowledge on the association between urinary lead concentration and renal profile is limited, especially on the characteristic of urinary lead that could aggravate existing kidney disease. This study aims to determine the concentration of urinary lead with serum creatinine and blood urea nitrogen in chronic kidney disease patients and to identify the influences of confounding factors and the blood pressure on the chronic kidney disease patients. Graphite Furnace Atomic Absorption Spectrometer was used to determine the urinary lead concentration. The differences and correlation of urinary lead with serum creatinine, blood urea nitrogen and diastolic blood pressure between the chronic kidney disease patients and control groups were assessed using Mann Whitney U and Spearman correlation tests. Our findings indicated a significantly higher urinary lead concentration in the chronic kidney disease group compared to the control group ( $p-=0.002$ ). Nevertheless, there is a weak relationship between urinary lead with serum creatinine, blood urea nitrogen and diastolic blood pressure in the chronic kidney disease group ( $\mathrm{r}$ values: $-0.123,0.101$, and 0.127$)$. In addition, sociodemographic factors did not influence the concentration of urinary lead $(p>0.05)$. The urinary lead concentration in the chronic kidney disease group is not substantial, thus the evidence of urinary lead accumulation in chronic kidney disease group who have yet to start renal replacement therapy is inconclusive.
\end{abstract}

\section{KEYWORDS}

blood urea nitrogen, chronic kidney disease, diastolic blood pressure, serum creatinine, urinary lead.

\section{INTRODUCTION}

$\mathrm{Pb}$ (lead) is a mixture of 4 stable isotopes, 208Pb (51-53\%), 206 Pb (23.5$-27 \%), 207 \mathrm{~Pb}(20.5-23 \%)$, and $204 \mathrm{~Pb}(1.35-1.5 \%)$ that were formed vary by ores or rocks and naturally occurring elemental within the earth's crust (Cao et al., 2015). Due to its properties, Pb has become a common metal used in pipes, welding and storage batteries where demand is high in many industries. As a result of its extensive usage, it has been discovered that the concentration of $\mathrm{Pb}$ in the environment is essentially relatively high in many cities in developing and developed countries (Osman et al., 2005).

In Sabah, $\mathrm{Pb}$ contamination has been reported before in which the soil and crops in Ranau were found to have exceeded the permissible Pb level. Most probably the contamination originated from the abandoned copper mining site in the surrounding areas. Moreover, the geological area in Ranau is known to be rich in mineral elements compared to other places in Sabah, thus the $\mathrm{Pb}$ contamination could have also come from natural contamination from the geological material in the soil which contained $\mathrm{Pb}$ content (Abdul Aziz et al., 2015). This is evidenced by a study which reported that the concentrations of $\mathrm{Pb}$ in the paddy soil and rice grains in Papar exceeded the permissible limits for human consumption in rice grains by FAO/WHO (2002) (Payus et al., 2015; FAO/WHO, 2002). Rice grains are the main source of food intake for the local population. In addition, the contamination could have also originated from the busy transportation activities surrounding the main roads of the oil and gas industrial areas near Kimanis.

At present, in most countries, these metals are already known as a toxic element in the human body, particularly if they reach the level of action (Karrari et al., 2012). Evidence has also shown that chronic exposure to $\mathrm{Pb}$, even in a small but significant amount, can cause chronic kidney disease owing to $\mathrm{Pb}$ nephropathy. Information on $\mathrm{U}-\mathrm{Pb}$ toxicity and its adverse effects is important for the understanding of $\mathrm{Pb}$ nephropathy in the identification of outcomes for patients with early stage of kidney disease. The small amount of $\mathrm{Pb}$ that leaves in urine every day can act as a positive sign and make it available for study. Previous research has shown that long-term exposure to $\mathrm{Pb}$ may represent significant toxicity and $\mathrm{Pb}$ nephropathy, which is manifested as gradually progressive interstitial nephritis (Evans and Elinder, 2011; Subha et al., 2012). Associations have also previously been recorded between increased SCr and higher levels of $\mathrm{Pb}$ (Weaver et al., 2003). In connection with this claim, also concluded that there is a significant association between the renal outcome and the U-Pb (Buser et al., 2015). Therefore, the compromised renal function in the CKD group can be an explanation of the accumulation of $\mathrm{Pb}$ in the body which resulted in an increased level of $\mathrm{Pb}$ in the urinary excretion and could increase the risk of their existing kidney disease (Orr and Bridges, 2017). However, the relationship between the U-Pb concentration in CKD

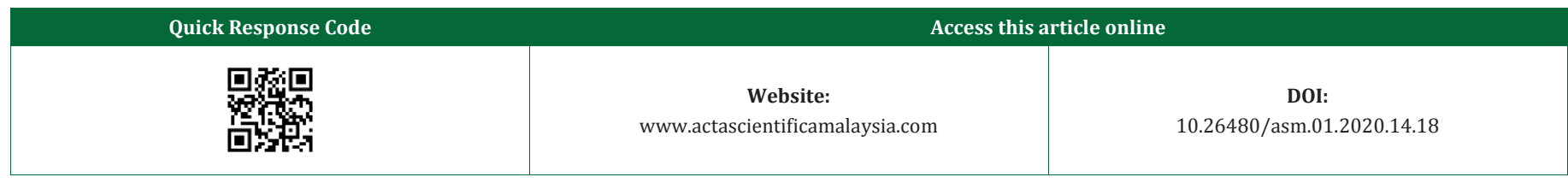


patients and its effect on the levels of SCr, BUN, and blood pressure remains uncertain (Spector et al., 2011).

Most of the studies used accurate measurements of renal function, such a s SCr,BUN, as well as blood pressure. Although most of the previous studi es have beenreported on the effects of $\mathrm{Pb}$, there are only a few studies in which the renal outcome is significantly increased (Li et al., 2008). The concern is, however, whether there is 'reverse causality' where U-Pb concentration is actually increased as a result of decreased renal function in populations with CKD. Due to the fact that the $\mathrm{Pb}$ element can cause accumulation in the CKD population, accumulative activities also may lead to potential nephrotoxicity and may disrupt the physiological function of the kidney. Some literature may indicate that the condition may be a reverse causation, especially those at a late stage of renal disease (Skerving and Bergdahl, 2015). Correlation between U-Pb concentration and renal outcome has been widely observed in the general population of another developing country. However, most of the previous research involves populations of children or lead workers with relatively little information on the population of CKD. In addition, no action level for U-Pb concentration in CKD population was determined in the previous study. While more evidence is needed to explain the mechanisms, a comprehensive understanding of the U-Pb concentration in the CKD population may help to understand the underlying mechanisms in order to discover novel diagnostic, prognosis and treatment approaches to $\mathrm{Pb}$ nephropathy.

The main objectives of this research are to study the concentration of $\mathrm{U}$ $\mathrm{Pb}$ in chronic kidney disease patient who was referred to the nephrology clinic at Queen Elizabeth Hospital. This study will illustrate the difference of $\mathrm{U}-\mathrm{Pb}, \mathrm{SCr}, \mathrm{BUN}$ concentration, and diastolic BP between CKD and control groups and identify the influences of U-Pb concentration on diastolic BP among the participants after controlling the confounding factors. Based on previous research, our study hypothesis is that the level of SCr, BUN, and BP would also increase with the accumulation of U-Pb in the CKD population.

\section{Methodology and Material}

This is a single-center cross-sectional study at the Nephrology Health Care Clinic in Queen Elizabeth Hospital, Kota Kinabalu. The hospital caters for patients from urban and rural areas around Ranau and Kimanis. Most of the patients presented to this clinic are newly diagnosed as CKD and are referred here to be assessed by physicians. They may suffer from different stages of decreased renal function, ranging from mild and moderate kidney failure (GFR: $>90 \mathrm{~mL} /$ minute $/ 1.73 \mathrm{~m} 2$ ) to stage 4 kidney failure (GFR: $<29 \mathrm{~mL} /$ minute $/ 1.73 \mathrm{~m} 2$ ) and require the necessary treatment to avoid further damage to their kidney. For comparison purposes, patients from Papar district Hospital who seek treatment for minor medical conditions such as cough, colds or hay fever at the Outpatient department and found to have healthy kidney functions were recruited as the control group.

\subsection{Ethical approval and consent}

The study protocol was approved by the Medical Research Ethics Committee of University Malaysia Sabah (JKEtika 3/17,4) and the Malaysian Medical and Research Ethics Committee (MREC), Ministry of Health Malaysia (NMRR-17-2625-38629). Furthermore, both study sites also received permission from the hospital directors. All respondents were required to sign a written informed consent form before enrollment.

\subsection{Patient background}

The sample selection for this study was described in a previous study (Abdul et al., 2015). Purposive sampling was used. Patients who visited the morning clinic session, aged 18 to 70 years, and agree to participate were selected. Pediatrics patients, pregnant women, patients who are undergoing RRT therapy (hemodialysis), and those with renal function less than $15 \mathrm{~mL} /$ minute $/ 1.73 \mathrm{~m}^{2}$ were excluded.

\subsection{Sample size}

The sample size was determined based on the formula $\mathrm{N}=\left(4.0 \mathrm{X} \partial^{2}\right) / 5^{2}$ suggested by a previous researcher (Snedecor and Cochran, 1980). Using the standard deviation for U-Pb concentration $(16 \mu \mathrm{g} / \mathrm{g})$ by a researcher, total sample size required was 41 (Nina et al., 2011). For quality purposes, the number was inflated to 60 samples for each group (60 CKD group, 60 control groups), making a total of 120 samples required for this study.

\subsection{Sampling method}

A previous researcher described the collection of the urine sample, in which $10 \mathrm{ml}$ of spot urine sample was collected with the aseptic technique using a $250 \mathrm{ml}$ acid-cleaned polypropylene bottles containing $0.2 \mathrm{ml}$ nitric acid $0.2 \mathrm{ml}$ (HNO3 69.5\%) as preservatives (Johan et al., 2014). The urine sample was then immediately transported in cold box to the laboratory of the Faculty of Engineering in University Malaysia Sabah immediately 24 hours. In addition, blood samples were taken from each patient during the clinic visit to determine the SCr and BUN levels. The results can be traced from the pathological laboratories of both hospitals.

\subsection{Graphite Furnace Atomic Absorption Spectrophotometer}

The instrumentation used to determine the $\mathrm{U}-\mathrm{Pb}$ concentration is the Agilent SpectrAA-400Z Deuterium and Zeeman GFAAS. This instrument is associated with a high capability, reliability, and accuracy in analyzing U$\mathrm{Pb}$. This optical instrument system improves the graphite furnace power supply circuit to ensure high sensitivity. By using a standard hollow cathode lamp, the spectrophotometer can be used to analyze $\mathrm{Pb}$ element in the urine. The calibration curve, sample check, standard check, and other QC functions are able to further enhance data reliability. The UMS Faculty provided ultrapure water and $1000 \mu \mathrm{g} / \mathrm{L} \mathrm{Pb}$ stock standard solutions (traceable to SRM from NIST Pb $\left(\mathrm{NO}_{3}\right)_{2}$ in $\mathrm{HNO}_{3} 0.5 \mathrm{~mol} / \mathrm{l} 1000$ $\mathrm{mg} / \mathrm{l}$ PbCertipur $($ ). The quality control during the experimental procedures was described in detail by a previous study (Christine, 2010). Nitric acid (HNO3 69.5\%, type analytical Use, Cheshire UK) were used for urine digestion, and $2 \%$ nitric acid was used as an internal standard. All polypropylene bottles were thoroughly washed and then soaked overnight in nitric acid and rinsed clean with de-ionized water and stored in laminar flow hoods before use. To form the $10 \mu \mathrm{g} / \mathrm{mL}$ intermediate $\mathrm{Pb}$ standard pipet, $1.0 \mathrm{~mL}$ stock $\mathrm{Pb}$ standard and de-ionized water were added by using glass pipettes to a $100 \mathrm{~mL}$ volumetric flask and the final volumes were carefully made up to $100 \mathrm{~mL}$. For all calibration standards, the concentration of $100 \mu \mathrm{g} / \mathrm{L}$ was prepared by pipetting $1.0 \mathrm{~mL}$ intermediate standard solution to be diluted to $100 \mathrm{~mL}$; similarly, for 200 and $300 \mu \mathrm{g} / \mathrm{L}, 2.0$ and $3.0 \mathrm{~mL}$ intermediate standard solutions were pipetted and diluted to $100 \mathrm{~mL}$. The standard solutions must be prepared fresh daily. The calibration curve was determined based on standard solutions of 10,20 , and $30 \mu \mathrm{g} / \mathrm{dl}$ and the limit of detection for $\mathrm{U}-\mathrm{Pb}$ is 0.001 $\mu \mathrm{g} / \mathrm{L}$. A pilot study was carried out to determine the accuracy of the instrument analyzer. All working calibration standards for urine sample CKD and control group were prepared in the same manner. The result of the standards calibration curve indicated a linear value parameter with a high correlation coefficient value of $>0.97$.

\subsection{Measuring of Urinary Creatinine Concentration}

Urinary creatinine was measured with an auto-analyzer instrument to correct any large variation in the individual spot urine (Agnes et al., 2012; Fumihiro and Shunichi, 2010). The U-Pb concentration was subsequently divided by urinary creatinine to reduce the variation of each sample based on this formula: $(\mu \mathrm{g} / \mathrm{L} \mathrm{Pb} \times 100) /(\mathrm{mg} / \mathrm{dl}$ creatinine) (Analytical procedures for the determination of lead in blood and Urine, 2001).

\subsection{Statistical analysis}

Data analyses were performed using SPSS version 21. U-Pb concentration was expressed as the mean \pm standard deviation and range values at $95 \%$ confidence intervals. The p-value of less than 0.05 was considered significant. Comparison of U-Pb, SCr, BUN, and diastolic BP was carried out between the CKD group and the control subjects using the Mann Whitney $\mathrm{U}$ test and t-test. The correlation of U-Pb concentration with $\mathrm{SCr}$ and BUN were determined with Spearman Correlation and Pearson correlation for diastolic BP. Following that, GLM was performed to determine the effects of U-Pb concentration and diastolic BP after controlling for any confounding factors.

\section{RESULT}

The individual U-Pb concentration was $0.007 \mu \mathrm{g} / \mathrm{g}$ to $37.3 \mu \mathrm{g} / \mathrm{g}$ (Figure 1). Meanwhile, the mean U-Pb for the CKD group was $4.1 \mu \mathrm{g} / \mathrm{g}$ with a standard deviation of 7.92. The mean $\mathrm{U}-\mathrm{Pb}$ for the control group was $3.8 \mu \mathrm{g} / \mathrm{g}$ with a 
standard deviation value of 2.93. The maximum concentration for the CKD group was $37.3 \mu \mathrm{g} / \mathrm{g}$ as compared to $11.2 \mu \mathrm{g} / \mathrm{g}$ for the control group while the minimum concentration for the CKD group was $0.05 \mu \mathrm{g} / \mathrm{g}$ and $0.007 \mu \mathrm{g} / \mathrm{g}$ for the control group. Table 1 shows a statistically significant difference between the CKD and control groups with $\mathrm{p}$-value $=0.002$ $(<0.05)$. The median U-Pb concentration in the CKD group was 1.08 (IR 3.300), which was significantly lower than the control group (median 3.38, IR 1.4932).

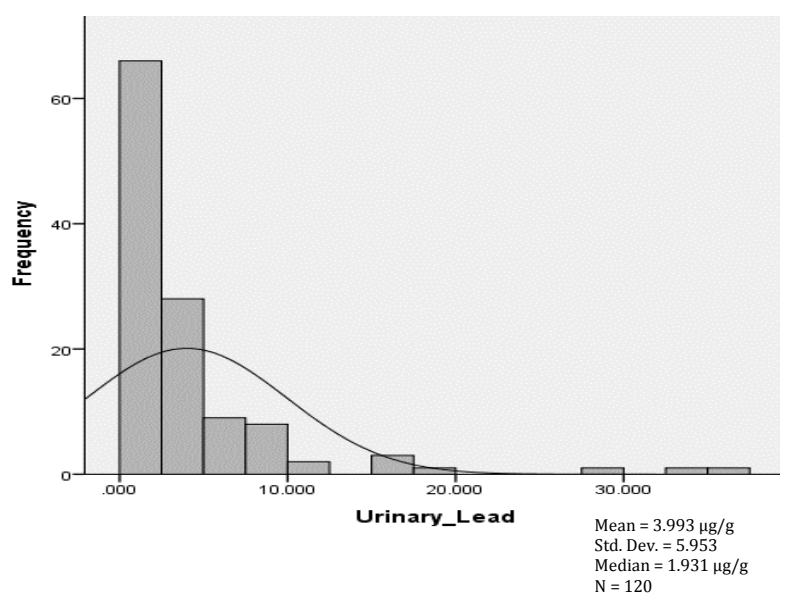

Figure 1: The distribution of $\mathrm{U}-\mathrm{Pb}$ concentration in study groups

\begin{tabular}{|c|c|c|c|c|c|c|}
\hline $\begin{array}{l}\text { rinary } \\
\text { ead }\end{array}$ & $\begin{array}{c}\text { Mean } \\
(\mu \mathrm{g} / \mathrm{g})\end{array}$ & $\begin{array}{c}\text { Median } \\
(\mu \mathrm{g} / \mathrm{g})\end{array}$ & $\begin{array}{c}\text { Max } \\
(\mu \mathrm{g} / \mathrm{g})\end{array}$ & $\begin{array}{c}\text { Min } \\
(\mu \mathrm{g} / \mathrm{g})\end{array}$ & $\begin{array}{c}\text { Z- } \\
\text { Statistic }^{a}\end{array}$ & $\begin{array}{c}P \\
\text { value }\end{array}$ \\
\hline $\begin{array}{l}\text { tudy } \\
\text { roups } \\
n=120 \text { ) }\end{array}$ & $3.9 \pm 5.95$ & 1.9 & 37.3 & 0.007 & 3.055 & $0.002^{\mathrm{b}}$ \\
\hline $\begin{array}{l}\text { KD } \\
\text { roup } \\
n=60 \text { ) }\end{array}$ & $4.1 \pm 7.92$ & 1.1 & 37.3 & 0.05 & & \\
\hline $\begin{array}{l}\text { ontrol } \\
\text { coup } \\
=60 \text { ) }\end{array}$ & $3.8 \pm 2.93$ & 3.3 & 11.2 & 0.007 & & \\
\hline
\end{tabular}

${ }^{a}$ Mann-WithneyU test was applied

${ }^{\mathrm{b}}$ significant at $\mathrm{p}<0.05$

Table 2 shows that the mean and SD values of SCr and BUN for the CKD group were higher than the control group. The SCr and BUN were significantly different between the two groups $(p<0.05)$. The diastolic BP in the CKD group was lower than the control group but the two-tailed pvalue was 0.067 , indicating no significant difference in diastolic BP between CKD and control group.

\begin{tabular}{|l|c|c|c|c|c|}
\hline \multicolumn{7}{|c|}{ Table 2: The levels of SCr, BUN, and Diastolic BP between the CKD } \\
group and control groups \\
\hline Variables & CKD (n = 60) & $\begin{array}{c}\text { Control } \\
(\mathbf{n = 6 0}\end{array}$ & $\begin{array}{c}\mathbf{z}^{-} \\
\text {statistic }^{\mathbf{a}}\end{array}$ & $\begin{array}{c}\text { t- } \\
\text { statistic }^{\mathbf{c}}\end{array}$ & $\begin{array}{c}\boldsymbol{P} \\
\text { value }\end{array}$ \\
\hline SCr & $192.3 \pm 181.49$ & $82.4 \pm 20.59$ & -5.005 & & $0.001^{\mathrm{b}}$ \\
$(\mu \mathrm{mol} / \mathrm{L})$ & $(39-1058)$ & $(38.6-135)$ & & & \\
& $8.0 \pm 6.19$ & $4.1 \pm 1.22$ & -4.455 & & $0.001^{\mathrm{b}}$ \\
BUN & $(6.9-31.7)$ & $(1.4-2.3)$ & & & \\
$(\mathrm{mmol} / \mathrm{L})$ & $82.8 \pm 13.63$ & $87.3 \pm 13.12$ & & $-1.8(118)$ & $0.067^{\mathrm{d}}$ \\
& $(129-61)$ & $(132-52)$ & & & \\
Diastolic & & & & & \\
BP & & & & & \\
$(\mathrm{mmHg})$ & & & & & \\
\hline
\end{tabular}

${ }^{a}$ Mann-WithneyU test was applied

${ }^{\mathrm{b}}$ significant at $\mathrm{p}<0.05$

${ }^{\mathrm{c}}$ Independent t-test was applied

${ }^{\mathrm{d}}$ significant at $\mathrm{p}>0.05$

The relationship between U-Pb with SCr, BUN, and diastolic BP for each group is shown in Table 3. The results indicated weak correlation $(\mathrm{r}=-$ $0.123,-0.101$, and $-0.127 ; \mathrm{p}<0.05$ ) in the CKD group. Similarly, there was also weak correlation between U-Pb with $\mathrm{SCr}$, BUN, and diastolic BP in the control group $(r=-0.193,0.127,-0.133)$.

\begin{tabular}{|l|c|c|c|c|}
\hline \multicolumn{5}{|c|}{ Table 3: Correlation of Urinary Lead with SCr, BUN and Diastolic BP in } \\
\hline Variables & $\begin{array}{c}\text { CKD } \\
\text { (n= 60) }\end{array}$ & $\begin{array}{c}\text { Urinary } \\
\text { Lead } \\
\boldsymbol{P} \text { value }\end{array}$ & $\begin{array}{c}\text { Control } \\
(\mathbf{n}=\mathbf{6 0})\end{array}$ & $\boldsymbol{P}$ value \\
\hline SCr $(\mu \mathrm{mol} / \mathrm{L})$ & $\mathrm{r}=-.123^{\mathrm{a}}$ & 0.35 & $\mathrm{r}=-.193^{\mathrm{a}}$ & 0.14 \\
$\begin{array}{l}\text { BUN } \\
(\mathrm{mmol} / \mathrm{L})\end{array}$ & $\mathrm{r}=-0.101^{\mathrm{a}}$ & 0.441 & $\mathrm{r}=0.127^{\mathrm{a}}$ & 0.33 \\
$\begin{array}{l}\text { Diastolic BP } \\
(\mathrm{mmHg})\end{array}$ & $\mathrm{r}=-0.127^{\mathrm{b}}$ & 0.33 & $\mathrm{r}=-.133^{\mathrm{b}}$ & 31 \\
\hline
\end{tabular}

aSpearman's rho correlation was applied

${ }^{b}$ Pearson correlation was applied

In this study, the GLM main effect was adjusted for each confounding factor. The relationship between $\mathrm{U}-\mathrm{Pb}$ concentration and diastolic $\mathrm{BP}$ after adjusted by age, gender, ethnicity, and residential area at univariate analysis suggested that $\mathrm{p}$-value for all the confounders were not significant ( $p=0.195, p=0.203, p=0.249, p=0.289$ respectively). The findings showed that sociodemographic factors did not influence the U-Pb concentration of the patients.

\section{DISCUSSIONS}

This study has two significant contributions. First, it is the first study to focus on the concentration of U-Pb among the local population in Malaysia. Secondly, this is one of the few studies that compare between CKD and control groups. This comparison was able to provide evidence for researchers to establish the safe concentration level of U-Pb. However, it should be noted that the significant values of $\mathrm{U}-\mathrm{Pb}$ concentration in this study were only related to the correction with urinary creatinine. Certain comparison is not possible due to the lack of literature and data on the U$\mathrm{Pb}$ correction with urinary creatinine.

Closer scrutiny on the $\mathrm{U}-\mathrm{Pb}$ concentration in this study did not reveal any substantial differences in U-Pb concentration mean between the CKD and control groups. A previous NHANES study in 2018 showed a higher concentration of U-Pb in the control group $(2.14 \mu \mathrm{g} / \mathrm{g})$ than the CKD group $(1.79 \mu \mathrm{g} / \mathrm{g})$ (Jin et al., 2018). By compassion, the U-Pb concentration for the healthy group in Korea was slightly higher than the control group in this study. However, the U-Pb concentration of all the 120 respondents in this study do not exceed the safety level (16 to $60 \mu \mathrm{g} / \mathrm{g}$ ) recommended by NIOSH (1994) and thus are not regarded as having Pb-toxicity (Lead in Blood and Urine, 1994).

Several possibilities may explain the concentration of U-Pb in both groups. Firstly, the U-Pb data in this study suggest that correction for dilution can result in different effects for individuals with different kidney function. For example, it may have a strong influence on urine samples with low $\mathrm{Pb}$ concentrations but little or no effects on samples with high $\mathrm{Pb}$ concentration. This situation may affect those with high urinary creatinine, especially CKD patients. Thus, they tend to have a lower concentration of $\mathrm{U}-\mathrm{Pb}$. Another possible explanation for this inconsistency may be related to $\mathrm{Pb}$ metabolism. Upon entering the body, $\mathrm{Pb}$ will be transported out from red blood cell membranes into plasma and is then filtered by the kidney throughout the urine within 30 days. However, due to impaired renal functions, CKD patients might not be able to excrete it rapidly from the kidney (Barbosa et al., 2005). This period of $\mathrm{Pb}$ accumulation may result in most of the retained $\mathrm{Pb}$ being circulated back to the bloodstream and stored in the bone (Patrick, 2006). Another previous study also reported the fact that decreased kidney function compromises its ability in removing $\mathrm{Pb}$, thus resulting in a lower concentration of $\mathrm{Pb}$ being excreted through urine (Tewodros et al., 2015).

In addition, this study revealed a statistical difference in the $\mathrm{SCr}$ concentration of the CKD and control groups, whereby the CKD group had a higher concentration of SCr and BUN. This can be caused by the decline in renal function to eliminate the waste product of metabolism generated from protein breakdown in the body, a phenomenon often presents in CKD patients (Chris Higgins, 2016). Interestingly, the findings of this study also revealed that the risk of getting higher diastolic BP might not necessarily confine to CKD patients. Our study echoed the findings of a previous study which reported that the mean value of diastolic BP of the control group in this study was comparable to the general population in Malmo, Sweden (DBP=87 mmHg, p-value = 0.001) (Angela et al., 2016). 
We also identified a weak correlation between $\mathrm{U}-\mathrm{Pb}$ and $\mathrm{SCr}$ in the CKD group in this study. By comparison, a scholar indicated a significant relationship between $\mathrm{U}-\mathrm{Pb}$ concentration and $\mathrm{SCr}(\mathrm{p}=0.04)$ (Ja et al., 2003). The different results from our study may be attributed to chelation therapy (Pizzorno, 2015). Our study also indicated a weak relationship between $\mathrm{U}-\mathrm{Pb}$ with BUN for both CKD and control groups. This finding was consistent with a previous study $(r=0.28, p=0.01)$. While it may be speculated that the association was not significant due to the fact that $\mathrm{SCr}$ and BUN concentration might not be high enough for detection until the very late stage of CKD (Gordon et al., 2009). In our study, not all of the participants were in the late stage of CKD. Compared to the control group, none of the participants recorded a higher than normal level of SCr and BUN of the U-Pb cutoff point.

While our results revealed higher diastolic BP in the control group compared to the CKD group, there was no significant association between $\mathrm{U}-\mathrm{Pb}$ and diastolic BP for both groups. In previous studies, only high concentration of $\mathrm{Pb}$ may potentially lead to hypertension. The expected confounding factor to this finding might be the asymptomatic high blood pressure among the control group who were only diagnosed during their first clinic visit. The finding showed that sociodemographic factors did not influence the concentration of U-Pb. This finding was not in sync with another study in which age and other confounding factors were consistently observed in populations with high Pb level (Agency for Toxic substances and Disease Registry, 2007).

While the results in this study may explain some of the outcomes of the independent variables, the small sample size could have reduced the strength of reported associations and insufficient to reveal some of the significant associations between the variables. Therefore, further validation with a bigger population best in a prospective cohort is needed to demonstrate if $\mathrm{U}-\mathrm{Pb}$ has associated with kidney disease in our society. Another limitation of this study is the U-Pb assessment will need further validation with the combination of BLL measurements by means of BLL as a comparison for better results to be made for both groups.

\section{CONCLUSIONS}

This study was also unable to prove that high $\mathrm{U}-\mathrm{Pb}$ is a significant risk of developing a high level of SCr, BUN, and diastolic BP as higher concentrations of $\mathrm{SCr}$, BUN, and diastolic BP were not associated with a higher level of $\mathrm{U}-\mathrm{Pb}$ concentration in both groups. Furthermore, the U-Pb concentration in the study group was still within the normal range based on the NIOSH (1994) reference range. Therefore, the correlation between $\mathrm{U}-\mathrm{Pb}$ and renal profile was weak at best. Additionally, there was no evidence of $\mathrm{Pb}$ accumulation in patients who have yet to start RRT. As such, our study also suggested that kidney disease per se does not lead to an increase in the body lead stores, thus there is no reverse causation which took place in the study group. However, the possibility of $\mathrm{Pb}$ accumulation may potentially be higher among ESRD patients who have started RRT and had low or no urine output. Previous studies presented a diverse reference range of $\mathrm{U}-\mathrm{Pb}$ concentration due to the substantial variation in spot urine. Therefore, new correction methods to enhance the standard creatinine-correction value simultaneously are needed to remove the influence of urine flow rate, especially among the CKD population. Further research should look into the impact of other variables such as BMI, lifestyle habits such as cigarette smoking and alcohol consumption, household income, duration and type of occupation, and source of water intake as these are potential risk factors of impaired renal functions.

\section{ACKNOWLEDGMENT}

"I, the Corresponding Author, declare that this manuscript is valid and original work. This manuscript or portions thereof are not under consideration by another journal or electronic publication and have not been previously published". This study was a self-funded research project and was partially supported by the Department of Community and Family Medicine and the Faculty of Engineering, University Malaysia Sabah to provide experimental tools and equipment for this project.

\section{CONFLICT OF INTEREST}

None declared

\section{ABBREVIATION AND SYMBOL}

ASTDR = Agency for Toxic Substances and Disease Registry

BLL $=$ Blood Lead Level

$\mathrm{BP}=$ Blood Pressure

BUN = Blood Urea Nitrogen

$\mathrm{CKD}=$ Chronic Kidney Disease

$\mathrm{FAO}=$ Food and Agriculture Organization

GLM $=$ General Linear Model

GFAAS = Graphite Furnace Atomic Absorption Spectrometer

IR = Interquartile Range

MREC $=$ Medical Review and Ethics Committee

NMRR $=$ National Medical Research Register

$\mathrm{Pb}=$ Lead

RRT $=$ Renal Replacement Therapy

$\mathrm{SCr}=$ Serum Creatinine

$\mathrm{U}-\mathrm{Pb}=$ Urinary Lead

$\mu \mathrm{g} / \mathrm{g}=$ Microgram per Gram

$\partial=$ Standard deviation

\section{REFERENCES}

Abdul Aziz, R., Abd Rahim, S., Sahid, I., Idris, W.M.R., Bhuiyan, M.A.R., 2015. Determination of Heavy Metals Uptake in Soil and Paddy Plants. American-Eurasian Journal of Agriculture and Environmental Sciences, 15(2), 161-164.

Abdul, H.P., Tasneem, G., Hassan, I.A., Salma, A.A., Mariam, S.A., Kapil, D.B., Naeem, U., Jamshed, A., Sadaf, S.A., 2015. Comparative evaluation of essential and toxic elements in the blood of kidney failure patients and healthy referents, Environ Monit Assess, 187, 37.

Agency for Toxic Substances and Disease Registry, 2007. Toxicological Profile for Lead: Atlanta (GA): Agency for Toxic Substances and Disease Registry (US), 21, 107

Agnes, C., Marc, N., Xavier, D., Thomas, L., Staffan, S., 2012. Alfred Bernard. Associations between proteins and heavy metals in urine at low environmental exposures: Evidence of reverse causality, Toxicology Letters, 210, 345- 352 .

Analytical Procedures for the Determination of Lead in Blood and Urine; Approved Guideline Serving the World's Medical Science Community Through Voluntary Consensus (Vol. 21) 2001 [cited 2017 Oct 23]. Available from: http://demo.nextlab.ir/getattachment/68165fbfa965-4e20-855d-9aa8f57588bb/CLSI-C40-A.aspx

Angela, G., Gerd, S., Yan, B., Niklas, F., Bo, H., Peter, N., Bjorn, F., Gunnar, E., Lars, B., 2016. Low-level exposure to lead, blood pressure and hypertension in a population-based cohort, Environmental Research, $149,157-163$.

Barbosa Jr., F., Tanus-Santos, J.E., Gerlach, R.F., Parsons, P.J., 2005. A Critical Review of Biomarkers Used for Monitoring Human Exposure to Lead: Advantages, Limitations, and Future Needs, Environmental Health Perspectives, 113, 12

Buser, M.C., Ingber S.Z., Raines, N., Fowler D.A., Scinicariello, F., 2015. Urinary and blood cadmium and lead and kidney function: NHANES 2007-2012. International Journal of Hygiene and Environmental Health, 7.

Cao, S.Z., Duan, X.L., Zhao, X.G., Wang, B.B., Ma, J., Fan, D.L., Sun, C.Y., He, B., Wei, F.S., Jiang, G.B., 2015. Levels and source apportionment of children's lead exposure: Could urinary lead be used to identify the levels and sources of children's lead pollution? Environmental Pollution, 199, $18 \mathrm{e} 25$.

Chris Higgins. Urea and the clinical value of measuring blood urea concentration. 2016. [2019 Mac 12]. Available from https://acutecaretesting.org/-

/media/acutecaretesting/files/pdf/urea-and-the-clinical-value-ofmeasuring-blood-ans-approved.pdf

Christine, F.D.S., 2010. Determination of Lead in Urine by GFAASDeuterium and Zeeman Background Correction, 2010 [cited 2017 Sept 13]. Available from: www.agilent.com/chem. 
Evans, M., Elinder, C.G., 2011. Chronic renal failure from lead: myth or evidence-based fact? Kidney International, 79, 272-279.

FAO/WHO. 2002. Schedule 1 Maximum and Guideline for Contaminants and Toxins in Food. Codex Alimentarius-General Standards for Contaminants and Toxins in food. Joint FAO/WHO Food Standards Programme, Codex Committee, Rotterdam. Reference CX/FAC 02/16, 2002 [Cited 2017 Mei 1]. Available from http://www.fao.org/input/download/standards/17/CXS_193e_2015. pdf

Fumihiro, S., Shunichi, A., 2010. Adjustment of Creatinine-Adjusted Value to Urine Flow Rate in Lead Workers, Arch Environ Health: An International Journal, 51, 4, 329-333

Gordon, C.H., Kent, J.J., Samuel, M.C., 2009. A comparison of rat chronic progressive nephropathy with human renal disease-implications for human risk assessment. Critical Reviews in Toxicology, 39(4), 332-346.

Ja, L.L., Dan, T.L.T., Kuang, H.H., Chun, C.Y., 2003. Environmental Lead Exposure and Progression of Chronic Renal Diseases in Patients without Diabetes. The New England Journal of Medicine, 348, 277-86.

Jin, R.F., Zhu, X.Z., Shrubsole, M.J., Yu, C., Xia, Z.L., Dai, Q., 2018. Associations of renal function with urinary excretion of metals: Evidence from NHANES 2003-2012. Environment International, 121, 1355-1362.

Johan, N.S., Maria, H., Thomas, L., Leif, N., Staffan, S., Ingvar, A.B., 2014. Investigation of lead concentrations in whole blood, plasma and urine as biomarkers for biological monitoring of lead exposure, Journal of Exposure Science \& Environmental Epidemiology, 24, 51-57.

Karrari, P., Mehrpour, O., Abdollahi, M., 2012. A systematic review on status of lead pollution and toxicity in Iran; Guidance for preventive measures. DARU J Pharm Biomed Central Ltd.

Lead in Blood and Urine: Method 8003, Issue 2, NIOSH Manual of Analytical Methods (NMAM), Fourth Edition, 8/15/94, 1994 [Cited 2017 Aug 10]. Available from: https://www.cdc.gov/niosh/docs/2003154/pdfs/8003.pdf

Li, H.L., Sze, Y.C., Fang, Y.W., Jonathan, J.H.C., Hsien, W.K., 2008. Renal dysfunction and hyperuricemia with low blood lead levels and ethnicity in community-based study, Science of the Total Environment, 401, 3943.

Nina, M., Joseph, C., Ronald, H., Neil, R., 2011. EDTA chelation therapy in the treatment of toxic metals exposure, Spatula DD, 1(2), 81-89. DOI 10.5455/spatula.20110504045803

Orr, S.E., Bridges, C.C., 2017. Chronic Kidney Disease and Exposure to Nephrotoxic Metals, International Journal of Molecular Sciences, 18, 1039.

Osman A.L., El Tallawy, H.N., Hassan, H.A., Awad, H.A.M., Hamed, S.A., Hakeem, N.A., Moneim, M.A., 2005. Prevalence of Lead Toxicity Among Secondary School Students in Sohag City and Its Impact on Cognitive Functions, Alexandria Journal of Pediatrics, 19(1).

Patrick, L., 2006. Lead Toxicity, A Review of the Literature. Part I: Exposure, Evaluation, and Treatment, Alternative Medicine Review, 11,

Payus, C., Abu Talip, A.F., Hsiang, T.W., 2015. June. Heavy Metal Accumulations in Paddy Cultivation Area of Kompipinan, Papar District, Sabah. Journal of Sustainability Science and Management, 10(1), 76-86.

Pizzorno, J., 2015. Is Challenge Testing Valid for Assessing Body Metal Burden? Journal of Integrative Medicine, 14, 4.

Skerfving and Bergdahl. 2015. LEAD, Chapter 43, Handbook on the Toxicology of Metals 4E: Elsevier, 942, 953.

Snedecor, G.W., Cochran, W.G., 1980. Statistical Method. Seventh Edition. Iowa, US, The Iowa States University Press: World Cat.

Spector, J.T., Acien A.N., Fadrowski J., Guallar E., Jaar, B., Weaver, V.M., 2011. Associations of blood lead with estimated glomerular filtration rate using MDRD, CKD-EPI and serum cystatin C-based equations. Nephrology Dialysis Transplantation, 26, 2786-2792.

Subha, P.M., Rajan, A.S., Jothimalar, S.S., 2012. Blood Lead in End-Stage Renal Disease (ESRD) Patients who were on Maintainence Haemodialysis. Journal of Clinical and Diagnostic Research, 6(10), $1633-1635$

Tewodros, R., Marc, J., Herath, M., Peter, M., 2015. Nephrotoxic contaminants in drinking water and urine, and chronic kidney disease in rural Sri Lanka. Science of the Total Environment, 574-585.

Weaver, V.M., Lee, B.K., Ahn, K.D., Lee, G.S., Todd, A.C., Stewart, W.F., Wen, J., Simon, D.J., Parsons, P.J., Schwartz, B.S., 2003. Associations of lead biomarkers with renal function in Korean lead workers, Occupational and Environmental Medicine, 60, 551-562.

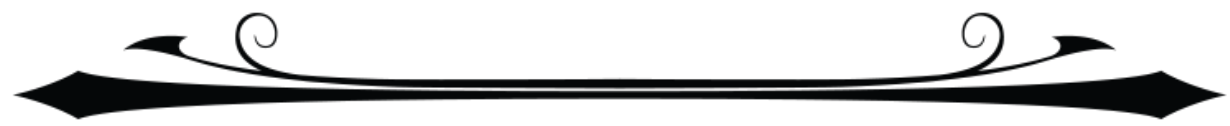

